\title{
GAMBARAN EFEKTIVITAS PENANGANAN NYERI POST OPERASI APPENDISITIS DI RSUD UNDATA PALU TAHUN 2019
}

\author{
Nur Afni Ismail ${ }^{1}$, Salmah Suciaty ${ }^{1}$, Ruslan Ramlan Ramli ${ }^{1 *}$ \\ ${ }^{1}$ Program Studi pendidikan Dokter, Fakultas Kedokteran Universitas Alkhairaat, Jl. Diponegoro Palu \\ 94221, Sulawesi Tengah, Indonesia \\ *Corresponding author: Telp: +6282225257575, email: ramlanruslan@gmail.com
}

\begin{abstract}
ABSTRAK
Angka kejadian nyeri pasca Apendektomi masih tinggi. Pasien yang mengalami nyeri yang cukup parah berdampak buruk terhadap lama perawatan dan produktivitasnya. Nyeri pasca Apendektomi sebaiknya ditekan hingga penderita bebas nyeri, karena nyeri tidak hanya mengakibatkan penderitaan pasca apendektomi saja, tetapi bila tidak tertangani dengan baik maka dapat berdampak dikemudian hari dan berisiko menimbulkan nyeri kronis, nyeri persisten dan depresi pasca operasi. Semakin parah nyeri yang dirasakan pasien di rumah sakit berarti terjadi penurunan efektivitas penanganan nyeri dan pelayanan kesehatan sehingga semakain buruk penilaian terhadap rumah sakit tersebut. Penelitian bertujuan untuk mengetahui gambaran efektivitas penanganan nyeri post operasi Appendisitis di RSUD Undata Palu, Sulawesi Tengah, Indonesia. Penelitian ini menggunakan metode deskriptif dengan pendekatan time series. Subjek sebanyak 14 pasien yang telah menjalani operasi Appendisitis diambil secara consecutive sampling. Pengumpulan data dilakukan pemeriksaan nyeri pada 6, 12, dan 24 jam post Operasi Appendisitis. Analisis data menggunakan perangkat lunak SPSS 25 dan Microsoft Office Excel 2016. Hasil yang diperoleh pada penelitian ini ialah distribusi penderita post operasi Appendisitis berdasarkan kategori skor NRS pada 6 jamdan 12 jam post operasi apendisitis adalah sama yaitu terbanyak ditemukan pada penderita dengan NRS $\geq 4$ sebanyak 14 orang (100.0\%). Sedangkan pada 24 jam terbanyak ditemukan pada penderita dengan NRS $\leq 3$ sebanyak 8 orang (57.1\%) dan terendah pada penderita dengan NRS $\geq 4$ sebanyak 6 orang (42.9\%). Maka dapat disimpulkan bahwa tingkat nyeri post operasi Appendisitis masih tinggi, yaitu sebanyak $100.0 \%$. Penderita memiliki skor NRS $\geq 4$ (tidak efektif) pada 6 dan 12 jam, dan $42.9 \%$ pada 24 jam post operasi Appendisitis.
\end{abstract}

Kata Kunci: Nyeri, Appendisitis, RSUD Undata

\section{ABSTRACT}

The incidence of post appendectomy pain is still high. Patients who experience severe pain have a detrimental effect on length of treatment and productivity. Post appendectomy pain should be suppressed until the patient is pain free, because pain does not only result in postappendectomy suffering, but if it is not handled properly, it can have an impact in the future and risk causing chronic pain, persistent pain and postoperative depression. The more severe the pain felt by the patient in the hospital, it means that there is a decrease in the effectiveness of pain management and health services so that the worse the assessment of the hospital is. This study aims to describe the effectiveness of postoperative appendicitis pain management at Undata Hospital Palu, Central Sulawesi, Indonesia. This study uses a descriptive method with a time series approach. The study subjects were 14 patients who had undergone appendectomy who were taken by consecutive sampling. Data was collected by examining pain at 6 hours, 12 hours, and 24 hours after Appendicitis Surgery. Data analysis used SPSS 25 and Microsoft Office Excel 2016 software. The results obtained in this study were the distribution of postoperative appendicitis patients based on the NRS score category at 6 hours and 12 hours post appendicitis surgery was the same, namely 14 people were found with NRS $\geq 4$ (100.0\%) 
Meanwhile, at 24 hours the highest number was found in patients with NRS $\leq 3$ as many as 8 people (57.1\%) and the lowest in patients with NRS $\geq 4$ were 6 people (42.9\%). So it can be concluded that the postoperative pain level of appendicitis is still high, namely as much as 100.0\%. Patients had NRS scores $\geq 4$ (ineffective) at 6 and 12 hours, and 42.9\% at 24 hours postoperative appendicitis.

Keywords: Pain, Appendicitis, Undata Hospital

\section{PENDAHULUAN}

Apendektomi adalah operasi pengangkatan appendix vermiformis. Apendisitis didefinisikan sebagai pembengkakan lapisan dalam dari usus buntu yang menyebar ke bagian lainnya. Meskipun ada kemajuan diagnostik dan terapi dalam pengobatan, radang usus buntu tetap merupakan keadaan darurat klinis dan merupakan salah satu penyebab sakit perut akut yang paling umum. ${ }^{1}$ Penyakit apendisitis merupakan penyebab sakit perut yang parah didunia yang berhubungan dengan nyeri setelah operasi. ${ }^{2}$ Apendisitis dapat ditemukan pada semua umur, insidens tertinggi pada kelompok umur 20-30 tahun, insidens pada laki-laki lebih tinggi. ${ }^{3}$

Insidensi apendiktomi di Indonesia menempati urutan ke 2 (dua) dari 193 negara diantara kasus kegawatan abdomen lainnya. Dan apendiksitis menempati urutan keempat penyakit terbanyak di Indonesia setelah dispepsia, gastritis dan duodenitis, dan penyakit sistim cerna lain dengan jumlah pasien rawat inap sebanyak $28.040 .{ }^{6}$

Dalam beberapa tahun terakhir, kejadian radang usus buntu sangat menurun. Meskipun demikian, radang usus buntu tetap menjadi salah satu keadaan darurat bedah yang paling umum. $^{8}$ Apendektomi tetap menjadi satusatunya pengobatan kuratif radang usus buntu. ${ }^{1}$ Dampak dari operasi appendisitis ada beberapa efek samping dari appendisitis yaitu radang selaput perut, luka infeksi, infeksi saluran kemih, obstruksi usus, rasa nyeri, dan rasa lelah. ${ }^{9}$

Nyeri adalah rasa indrawi dan pengalaman emosional yang tidak menyenangkan sebagai mekanisme protektif untuk menimbulkan kesadaran terhadap kenyataan bahwa sedang atau akan terjadi kerusakan jaringan yang nyata atau berpotensi rusak. $^{10,11}$
Dari 30 pasien seluruhnya 30 pasien (100\%) mengalami tingkat nyeri post operasi apendisitis. $^{9}$

Dampak nyeri pada pasien post operasi akan meningkat dan mempengaruhi penyembuhan nyeri. Control nyeri yang penting setelah operesi, nyeri yang dapat dibebaskan mengurangi kecemasan, pernafasan yang lebih mudah dan dalam mobilitas dengan cepat. Pengkajian nyeri dan obat analgetik dapat mengurangi nyeri yang dirasakan. ${ }^{12}$ Penderita yang mengalami nyeri yang cukup parah berdampak buruk terhadap lama perawatan dan penurunun aktifitas sehingga produktivitas penderita bisa menurun. Semakin parah nyeri yang dirasakan pasien di rumah sakit berarti terjadi penurunan efektivitas penanganan nyeri dan pelayanan kesehatan sehingga semakain buruk penilaian terhadap rumah sakit tersebut.

\section{METODOLOGI}

Penelitian ini menggunakan metode observasional deskriptif dengan pendekatan cross sectional. Penelitian ini dilaksanakan pada 1 Juli - 1 Oktober 2019, yang bertempat di Ruangan Teratai dan Anggrek RSUD Undata palu, Provinsi Sulawesi Tengah.

\section{Populasi}

Populasi penelitian ini Penderita appendisitis yang telah di operasi apendektomi di RSUD Undata Palu 2019. Subyek penelitian Penderita appendisitis yang telah di operasi apendektomi di RSUD Undata Palu 2019 yang memenuhi kriteria penelitian.

\section{Sampel \\ Metode penentuan sampel yang digunakan dalam penelitian ini adalah metode sampel jenuh. Pengumpulan sampel menggunakan teknik consecutive sampling dengan mengumpulkan semua sampel setiap hari yang memenuhi kriteria penelitian.}




\section{HASIL DAN PEMBAHASAN}

\section{HASIL}

Penelitian ini dilakukan di RSUD Undata Palu terhadap 14 pasien yang telah di operasi apendiktomi sejak 1 Juni sampai 1 Oktober 2019. Pada penelitian ini semua sampel diberikan terapi analgesia ketorolac $30 \mathrm{mg}$ bolus intravena tiap 8 jam sebanyak $3 \times 1$ ampul . Data diperoleh dari pemeriksaan pada pasien setelah operasi apendiktomi yang selanjutnya diisi pada case report. Data yang didapatkan terdiri dari derajat nyeri pada 6 jam,12 jam, dan 24 jam pasca operasi. Hasil deskriptif statistik ditampilkan dengan sistematika sebagai berikut

1. Gambaran karakteristik pasien post operasi appendisitis berdasarkan jenis kelamin dan umur

Tabel 1. Distribusi karakteristik penderita post operasi appendicitis berdasarkan jenis kelamin pasien

\begin{tabular}{|c|c|c|}
\hline $\begin{array}{c}\text { Jenis } \\
\text { kelamin }\end{array}$ & $\mathrm{N}$ & $\%$ \\
\hline Laki-laki & 8 & $57.1 \%$ \\
\hline Perempuan & $\underline{6}$ & $42.9 \%$ \\
\hline Total & 14 & $100 \%$ \\
\hline
\end{tabular}

Dari tabel diatas didapatkan hasil dari 14 penderita post operasi apendisitis terbanyak berdasarkan jenis kelamin yaitu pada laki-laki sebanyak 8 orang $(57.1 \%)$ dan terkecil pada perempuan sebanyak 6 orang $(42,9 \%)$.

Tabel 2. Distribusi karakteristik penderita post operasi appendicitis berdasarkan umur pasien

\begin{tabular}{|c|c|c|}
\hline Umur (tahun) & $\mathrm{N}$ & $\%$ \\
\hline $17-25$ & 7 & $50,0 \%$ \\
\hline $26-35$ & 5 & $35,7 \%$ \\
\hline $36-45$ & 0 & $0 \%$ \\
\hline $46-55$ & 1 & $7,1 \%$ \\
\hline $56-65$ & $\underline{1}$ & $7,1 \%$ \\
\hline Total & 14 & $100 \%$ \\
\hline
\end{tabular}

Dari tabel diatas didapatkan hasil dari 14 penderita post operasi appendisitis terbanyak berdasarkan umur yaitu pada 17-25 tahun sebanyak 7 orang $(50.0 \%)$ dan terkecil pada umur 46-55 dan 56-65 tahun masing-masing sebanyak 1 orang $(7,1 \%)$.
2. Gambaran pasien post operasi appendisitis berdasarkan tingkat nyeri pada 6 jam, 12 jam dan 24 jam

Tabel 3. Distribusi penderita post operasi apendisitis berdasarkan skor 0-10 Numerical Rating Scale pada 6, 12, dan 24 jam

\begin{tabular}{cccc} 
Subyek & \multicolumn{3}{c}{ Skor 0-10 NRS } \\
\cline { 2 - 3 } Penelitian & $\begin{array}{c}\text { NRS 6 } \\
\text { Jam }\end{array}$ & $\begin{array}{c}\text { NRS 12 } \\
\text { Jam }\end{array}$ & $\begin{array}{c}\text { NRS 24 } \\
\text { Jam }\end{array}$ \\
\cline { 2 - 2 } 1. & 10 & 8 & 5 \\
2. & 6 & 4 & 2 \\
3. & 7 & 5 & 2 \\
4. & 7 & 4 & 3 \\
5. & 9 & 4 & 5 \\
6. & 10 & 8 & 4 \\
7. & 8 & 6 & 5 \\
8. & 10 & 5 & 2 \\
9. & 6 & 5 & 3 \\
10. & 8 & 6 & 2 \\
11. & 6 & 5 & 3 \\
12. & 5 & 4 & 3 \\
13. & 9 & 6 & 5 \\
14. & 8 & $\underline{5}$ & $\underline{4}$ \\
\hline
\end{tabular}

Dari tabel diatas dapat dijelaskan bahwa terjadi penurunan skor nyeri pada pasien post operasi appendisitis seiring dengan perubahan waktu yaitu 6,12 , dan 24 jam post operasi appendisitis, namun belum semua pasien yang mencapai skor NRS nyeri ringan (0-3) pada 24 jam post operasi appendisitis.

Tabel 4. Distribusi penderita post operasi apendisitis berdasarkan skor Numerical Rating Scale pada 6, 12, dan 24 jam

\begin{tabular}{|c|c|c|c|}
\hline Skor NRS & $\begin{array}{l}\text { NRS } 6 \\
\text { jam } \\
\text { n }(\%)\end{array}$ & $\begin{array}{l}\text { NRS } \\
12 \text { jam } \\
\text { n }(\%)\end{array}$ & $\begin{array}{l}\text { NRS } \\
24 \text { jam } \\
\text { n }(\%)\end{array}$ \\
\hline $\begin{array}{l}\text { Nyeri Ringan } \\
(0-3)\end{array}$ & $0(0)$ & $0(0)$ & $\begin{array}{l}8 \\
(57.1)\end{array}$ \\
\hline $\begin{array}{l}\text { Nyeri Sedang } \\
(4-6)\end{array}$ & $\begin{array}{l}4 \\
(28,6)\end{array}$ & $\begin{array}{l}12 \\
(85,7)\end{array}$ & $\begin{array}{l}6 \\
(42.9)\end{array}$ \\
\hline $\begin{array}{l}\text { Nyeri Berat } \\
(7-10)\end{array}$ & $\begin{array}{l}10 \\
(71,4)\end{array}$ & $\begin{array}{l}2 \\
(14,3) \\
\end{array}$ & $0(0)$ \\
\hline Total & $\begin{array}{l}14 \\
(100)\end{array}$ & $\begin{array}{l}14 \\
(100) \\
\end{array}$ & $\begin{array}{l}14 \\
(100) \\
\end{array}$ \\
\hline
\end{tabular}


Dari tabel diatas didapatkan hasil dari 14 penderita post operasi apendisitis terbanyak berdasarkan skor NRSpada 6 jam post operasi apendisitis ditemukan pada skor NRS 7-10 sebanyak 10 orang $(71,5 \%)$, sedangkan pada Skor NRS pada 12 jam post operasi apendisitis ditemukan penderita terbanyak memiliki skor NRS 4-6 yaitu 12 orang $(85,71 \%)$. Dan skor NRS pada 24 jam post operasi apendisitis ditemukan penderita terbanyak memiliki skor NRS $0-3$ yaitu sebanyak 8 orang $(57,1 \%)$.

Tabel 5. Distribusi penderita post operasi apendisitis berdasarkan kategori Numerical Rating Scale pada 6 jam, 12 jam dan 24 jam

\begin{tabular}{llll}
$\begin{array}{l}\text { Kategori } \\
\text { Nyeri }\end{array}$ & $\begin{array}{l}\text { NRS } 6 \\
\text { jam }\end{array}$ & $\begin{array}{l}\text { NRS } \\
\text { jam }\end{array}$ & $\begin{array}{l}\text { 12 NRS } 24 \\
\text { jam }\end{array}$ \\
\cline { 2 - 4 } $\mathrm{n}(\%)$ & $\mathrm{n}(\%)$ & $\mathrm{n}(\%)$ \\
\hline $\begin{array}{l}\text { NRS } \leq 3 \\
\text { (Efektif) }\end{array}$ & $0(0)$ & $0(0)$ & $8(57.1)$ \\
$\begin{array}{l}\text { NRS } \geq 4 \\
\text { (Tidak }\end{array}$ & 14 & 14 & \\
Efektif) & $(100.0)$ & $(100.0)$ & $6(42.9)$ \\
\hline Total & $\begin{array}{l}14 \\
(100,0)\end{array}$ & $\begin{array}{l}14 \\
(100,0)\end{array}$ & $\begin{array}{l}14 \\
(100,0)\end{array}$ \\
\hline
\end{tabular}

Dari tabel diatas didapatkan hasil dari 14 penderita post operasi apendisitis yang memenuhi kriteria penelitian berdasarkan kategori Numerical Rating Scalepada 6 jamdan 12 jam post operasi apendisitis adalah sama yaitu terbanyak ditemukan pada penderita dengan NRS $\geq 4$ sebanyak 14 orang (100.0\%) sedangkan pada 24 jam terbanyak ditemukan pada penderita dengan NRS $\leq 3$ sebanyak 8 orang $(57.1 \%)$ dan terendah pada penderita dengan NRS $\geq 4$ sebanyak 6 orang $(42.9 \%)$.

\section{PEMBAHASAN}

Toxonomi Comitte of The International Assocation memaparkan bahwa nyeri pasca operasi sebagai sensori yang tidak menyenangkan dan pengalaman emosi yang berhubungan dengan kerusakan jaringan potensial atau nyata yang menggambarkan terminology suatu kerusakan. Tingkatan intensitas nyeri juga banyak dipengaruhi oleh faktor lainnya seperti teknik operasi, jenis kelamin dan usia.

Skala nyeri menggunakan numeric rating scale (NRS) efektif bila skala nyeri menggunakan NRS pada jam ke 24 pascaoperasi $<4$ dan tidak efektif bila NRS $\geq 4$. $^{13}$

Dari hasil penelitian distribusi penderita post operasi apendisitisyang dinilai tingkat nyeri berdasarkan kategori skor Numerical Rating Scale pada 24 jam dengan Nyeri ringan NRS 0-3 $(57.1 \%)$ penderita mengalami nyeri NRS $\leq 3$ (Efektif) sedangkan nyeri sedang NRS 4-6 (42.9\%) penderita mengalami nyeri NRS $\geq 4$ (Tidak Efektif). Hal ini sejalan dengan penelitian yang dilakukan oleh Prabandari dkk (2017) bahwa derajat nyeri pada jam ke-24 pasca operasi elektif yang dialami pasien adalah tidak nyeri NRS $0(12,6 \%)$ nyeri ringan NRS 1-3 (57,8\%), nyeri sedang NRS 4-6 $(26,9 \%)$, dan nyeri berat NRS $7-10(2,7 \%) .{ }^{13}$ Dari hasil penelitian distribusi penderita post operasi apendisitis yang dinilai tingkat nyeri berdasarkan kategori skor Numerical Rating Scale pada 24 jam terdapat nyeri ringan sebanyak8 $(57,1 \%)$ dan nyeri sedang sebanyak $6(42.9 \%)$. Hal ini sejalan dengan penelitian yang dilakukan oleh Diantari D A W, Wiguna A A, dan Niryana I W (2018) bahwa hari pertama terdapat sebanyak $75 \%$ nyeri ringan (1-3) dan 25\% nyeri sedang (4-6). Namun, tidak sejalan dengan penelitian terhadap 6 orang pasien dengan laparoskopi yang terdata pada hari pertama yaitu 50\% tanpa nyeri dan $50 \%$ nyeri ringan. ${ }^{14}$

Penelitian ini tidak sejalan dengan hasil penelitian dari Caecilia (2015) bahwa sebanyak 8 pasien yang telah menjalani operasi apendektomi sebelum dilakukan mobilisasi dini berada pada rentang kategori skala nyeri sedang (skala 4-6) berjumlah 2 orang $(25 \%)$ dan kategori skala nyeri berat (skala $7-10$ ) berjumlah 6 orang $(75 \%)$, dan dalam penelitian ini, tidak ada kalien post operasi apendektomi yang memiliki kategori tidak nyeri dan nyeri ringan sebelum dilakukan mobilisasi dini. ${ }^{15}$

secara teori menyatakan laki-laki memiliki sensitifitas yang lebih rendah (kurang mengekspresikan nyeri yang dirasakan secara 
berlebihan) dibandingkan wanita atau kurang merasakan nyeri. $^{16,17}$

Sedangkan secara teori menyatakan lanjut usia (lansia) berespon terhadap nyeri dapat berbeda dengan cara berespon orang yang berusia lebih muda. ${ }^{17}$

\section{KESIMPULAN}

Berdasarkan hasil penelitian dari pengambilan data pada 14 sampel pasien yang telah di operasi apendisitis di RSUD Undata Palu tahun 2019, tentang gambaran efektivitas penanganan nyeri post operasi appendisitis di

\section{DAFTAR PUSTAKA}

1. Craig, S. 2018. Appendicitis, (online). (https://emedicine.medscape.com/article/77 3895-overview\#a1, diakses 16 Maret 2019).

2. Khorsand, A., Tadayonfar, M. A.-R., Badiee, S., Aghaee, M. A., Azizi, H., \& Baghani, S. Evaluation of the effect of reflexology on pain control and analgesic consumption after appendectomy. Journal Of Alternative And ComplementaryMedicine (New York, N.Y.). 2015 Des; 21(12): 774-80. (https://doi.org/10.1089/acm.2014.0270, diakses 15 Februari 2018).

3. Sjamsuhidajat R, de Jong W. Apendiks Vermiformis. Dalam: Buku Ajar Ilmu Bedah. Edisi 4. Jakarta: EGC, 2010; p. 777

4. Gul T, Khan M.A, Sahar S.

Epidemiological and demographic features of appendicitis and influences of several environmental factors. Pak J Surg. 2014; 30(3): 245-247.

(http://www.pjs.com.pk/journal_pdfs/jul_se p14/245.pdf, diakses 13 Februari 2018)

5. Haydar B, Reynolds P. Appendectomy. Infectious Disease Advisor (IDA). 2019. (https://www.infectiousdiseaseadvisor.com/ home/decision-support-inmedicine/anesthesiology/appendectomy/, diakses 13 Februari 2018)

6. Departemen Kesehatan RI. 2012. Kasus Appendicitis di Indonesia.
RSUD Undata Palu Tahun 2019, diperoleh kesimpulan sebagai berikut:

Efektivitas penanganan nyeri post operasi appendisitis di RSUD Undata masih kurang baik karena tingkat nyeri post operasi appendisitis masih tinggi, yaitu tertinggi pada skor $\geq 4$ pada 6 jam dan 12 jam post operasi appendistis masih sama yaitu 14 orang $(100,0 \%)$ dan pada 24 jam post operasi appendisitis sebanyak 6 orang (42.9\%). Untuk harapan bebas nyeri tidak didapatkan. Namun, pada 24 jam post operasi appendisitis didapatkan penurunan nyeri yang efektif dengan skor $\leq 3$ sebanyak 8 orang $(57,1 \%)$.

7. Nurfanida L. 2015. Panduan Madiri Melacak Penyakit. Jakarta : Lintas kata

8. Santacroce, L. 2017. Appendectomy, (online). https://emedicine.medscape.com/article/195 778-overview\#showall, diakses Tanggal 11 Maret 2018,

9. Faridah, N.S. 2015. Penurunan Tingkat Nyeri Pasien Post Op Apendisitis Dengan Tehnik Distraksi Nafas Ritmik. Skripsi diterbitkan. Lamongan : Program Studi S1 Keperawatan STIKES Muhammadiyah Lamongan.https://stikesmuhla.ac.id/wpcontent/uploads/68-74-Virgianti-NurFaridah.pdf, diakses 11 Maret 2018).

10. IASP. 2017.Pain. International association of the study of pain, Washington D.C. (https://www.iasppain.org/Education/Content.aspx?ItemNu mber=1698\#Pain,diakses 12 Maret 2018).

11. Sherwood, L. 2014. Fisiologi Manusia: Dari Sel Ke Sistem. Edisi 8.

Diterjemahkan oleh Brahm U. Pendit. 2014. Jakarta: Penerbit Buku Kedokteran EGC. Hal 207-210

12. Faridah V. (2015). Penurunan Tingkat Nyeri Pasien Post Op Apendisitis dengan Teknik Distraksi Nafas Ritmik. Jurnal Studi Keperawatan Vol.07,No.02,Agustus 2015, 7(2).

13. Prabandari DA, Indriasari I, Maskoen TT. 2018. Efektivitas Analgesik 24 Jam Pascaoperasi Elektif di RSUP Dr. Hasan Sadikin Bandung Tahun 2017. Vol 6(2). 
http://journal.fk.unpad.ac.id/index.php/jap /article/view/1221, diakses pada 26 Desember 2019

14. Diantari DAW, Wiguna NAA, Niryana I.W. 2018. Gambaran evaluasi tingkat nyeri pasien pasca operasi radang usus buntu dengan bedah terbuka dan laparoskopi di Rumah Sakit Umum Pusat Sanglah Denpasar tahun 2016. Vol 9(2):100-106.

https://isainsmedis.id/index.php/ism/articl e/viewFile/158/180, diakses pada 26 Desember 2019

15. Pristahayuningtyas CY. 2015. Pengaruh Mobilisasi Dini Terhadap Perubhan Tingkat Nyeri Klien Post Operasi
Apendektomi di Ruangan Bedah Mawar Rumah Sakit Baladhika Husada Kabupaten Jember. http://repository.unej.ac.id/bitstream/handl e/123456789/65839/112310101024.pdf, diakses pada 26 Desember 2019

16. Black, J.M., \& Hawks, J.H. (2014). Medicalsurgical nursing clinical management for positive outcomes. (7th ed). St. Louis, Missouri: Elsevier Saunders

17. Smeltzer, S.C., \& Bare, B. (2012). Buku Ajar Keperawatan Medikal Bedah Brunner \& Suddarth, Volume 1 Edisi 12. Jakarta: EGC. 